\title{
Welding defects, Causes and their Remedies: A Review
}

\author{
Saadat Ali Rizvia ${ }^{1}$ and Wajahat Alib ${ }^{2}$ \\ ${ }^{1}$ Faculty member in UP, Jamia Millia Islamia, New Delhi, India \\ ${ }^{2}$ Mechanical Engineering Department, SCRIET (CCS University), Meerut, India
}

\begin{tabular}{l}
\hline \hline Article Info \\
\hline Article history: \\
Received July $02^{\text {th }}, 2019$ \\
Revised Aug $12^{\text {th }}, 2019$ \\
Accepted November $22^{\text {th }}, 2019$ \\
\\
Keywords: \\
Welding \\
welding defects \\
Parent metal (PM) \\
causes and remedies for \\
welding defects.
\end{tabular}

Corresponding Author:

\section{Saadat Ali Rizvia}

Faculty member in UP, Jamia Millia Islamia

New Delhi, India

Email: sarizvi1@jmi.ac.in

\section{INTRODUCTION}

Welding is a process of joining of two or more parts are coalesced at their contacting surfaces by application of heat and/or pressure. Welding is most commonly related to metal parts, but the process is also used for joining of plastics [1]. During the welding process, a lot number of defects occurred. What is Welding Defects? Welding Defects can be referred to as the irregularities formed in the given weld metal due to wrong welding process parameters or incorrect welding patterns, etc. The defect may differ from the desired weld bead shape, size, and intended quality [1]. Welding defects may produce either outside or inside of the weldment. Some of the defects may be allowed if the defects are under permissible limits but other defects such as cracks, porosity, improper penetration etc are never accepted [2].

\begin{abstract}
This review paper looks at the causes of welding defects and their in developing countries bearing poor quality and productivity due to the involvement of a number of the process parameter. Even in a completely controlled process, defects in the welding are observed anence welding process is also known as the process of which challenges explanation about the cause of welding welding the study is aimed at the research work. This will be beneficial in enhancing the yield of welding. Beside this, standardization (optimization) of process parameter for the entire cycle of manufacturing of the critical part is intended in the proposed work. This review paper also provides the accurate guideline to the quality control department to find welding defects and will help them to analyze defects which are not desired. In this review paper, an attempt has been made to categorise the various welding defects and their root causes of happening.
\end{abstract}

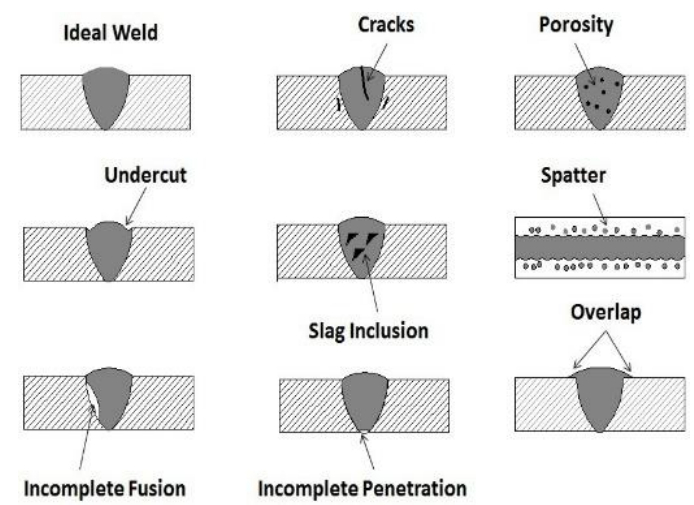

Figure 1 : Various welding defects 
Welding defects can be classified into two categories such as external and internal defects:

a. External Welding Defects:
1) Weld Crack
2) Undercut
3) Spatter
4) Porosity
5) Overlap
6) Crater

b. Internal Welding Defects:
1) Slag Inclusion
2) Incomplete Fusion
3) Necklace cracking
4) Incompletely filled groove or incomplete penetration

\subsection{External Welding Defects}

The various types of external defects with their causes and remedies are listed below:

\subsection{Weld Crack}

This is the most unwanted defect of all the other welding defects. Welding cracks can be present at the surface, inside of the weldment or at the heat affected zones (HAZ).

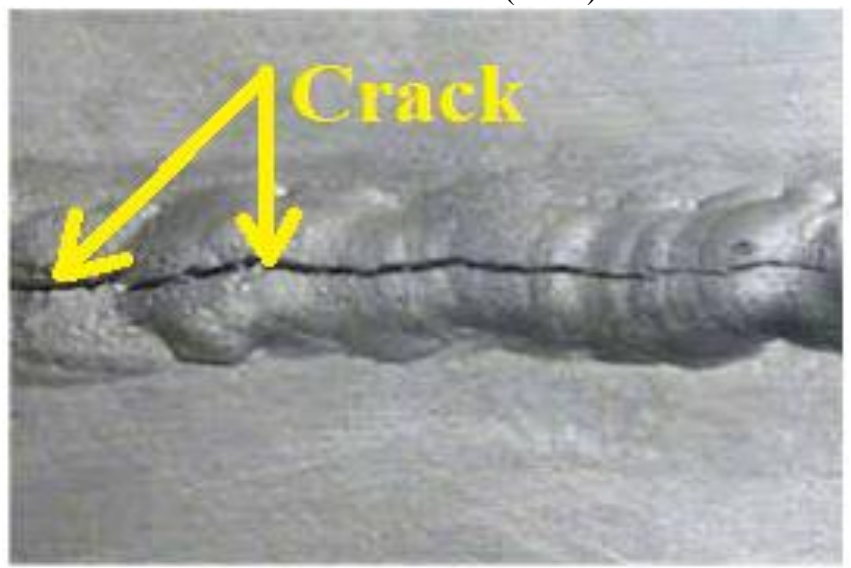

Fig.2 Crack in welding

Cracks are two types' i.e. hot crack and cold crack [3].

Hot Crack - It is more prominent during crystallization of weld joints where the temperature can raise more than $10,000{ }^{\circ} \mathrm{C}$. Cold Crack - The cracks produce at the end of the welding process is known as cold cracks. They also are known as hydrogen induced cold crack (HICC). They generally produced at HAZ. Sometimes cold crack is visible several hours after welding or even after a few days.

\subsubsection{Causes of Weld Crack:}

1. Poor ductility of the parent metal (PM).

2. The rigidity of the joint which makes it difficult to expand or contract the metals.

3. High sulfur content and carbon also responsible for cold cracks.

4. Residual stress caused by the solidification shrinkage.

5. Contamination of parent metal (PM).

6. High welding speed but low current.

7. No, preheat before starting welding.

8. Poor joint design.

\subsubsection{Remedies for Weld crack:}


1. Preheating of the base metal (BM) weld and reducing the cooling speed joint helps in reducing crack.

2. Reduce the gap between the weld joints by using reasonable weld joints.

3. While welding releases the clamping force slowly which increases fill to capacity of welding material.

\subsection{Undercut}

When the base of metal melts away from the weld zone, then a groove is formed in the shape of a notch, then this type of defect is known as Undercut. It reduces the fatigue strength of the joint [4].

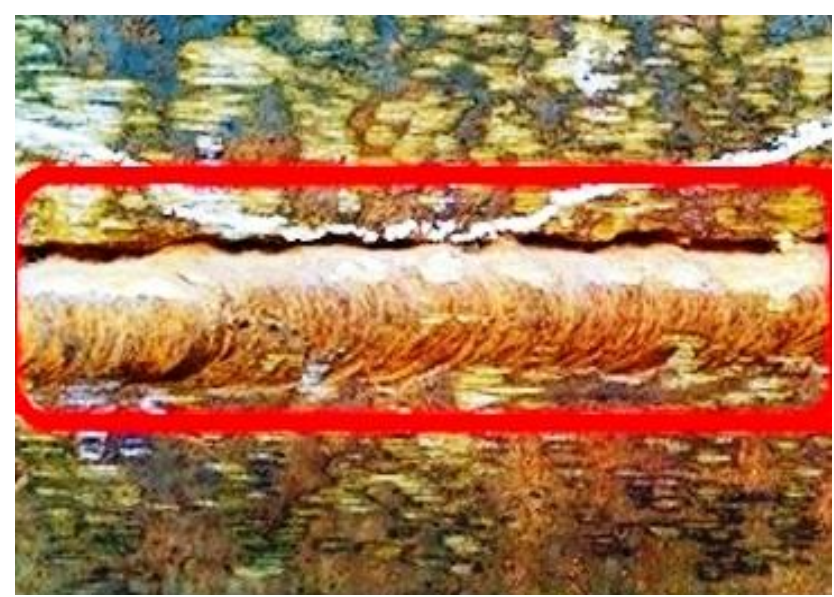

2.2.1 Causes of Undercut:

Fig.3 Undercut in welding

1. If the arc voltage is very high then this defect may occur.

2. If the wrong electrode is used or if the angle of the electrode is wrong, then also the defect may form.

3. Using a large electrode is also not advisable.

4. High electrode speed is also one of the reasons for this defect.

5. Too fast weld speed.

6. Incorrect usage of gas shielding.

7. Poor weld technique.

\subsubsection{Remedies for Undercut:}

1. Reduce the arc length or lower the arc voltage.

2. Keep the electrode angle from 30 to 45 degree with the standing leg.

3. The diameter of the electrode should be small.

4. Reduce the travel speed of the electrode.

5. Choose the correct shielding gas with the correct composition.

6. Use multi-pass technique.

\subsection{Spatter}

When some metal drops are expelled from the weld and remain stuck to the surface, then this defect is known as Spatter. 


\subsubsection{Causes of Spatter:}

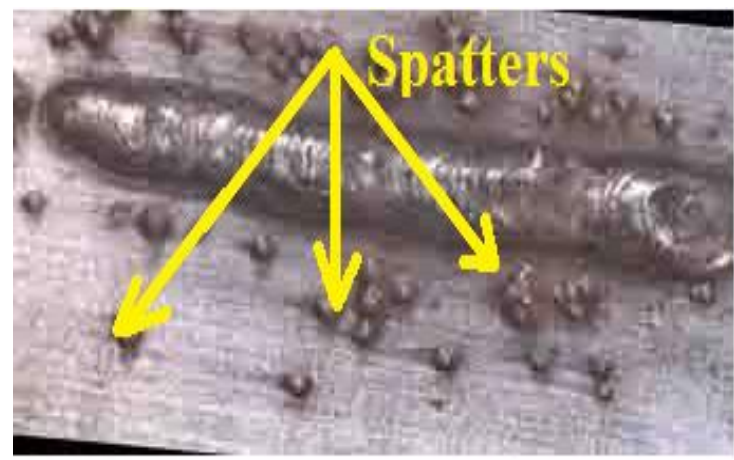

Fig.4 .Spatter

1. High Welding current can cause this defect.

2. The longer the arc the more chances of getting this defect.

3. Incorrect polarity.

4. Improper gas shielded may also cause this defect.

5. Voltage setting is too low.

6. The working angle of the electrode is too steep.

7. Surface is contaminated.

\subsubsection{Remedies for Spatter:}

1. Reducing the arc length and welding current

2. Using the right polarity and according to the conditions of the welding.

3. Increasing the plate angle and using proper gas shielding.

\subsection{Porosity}

Porosity in the condition in which the gas or small bubbles gets trapped in the welded zone.

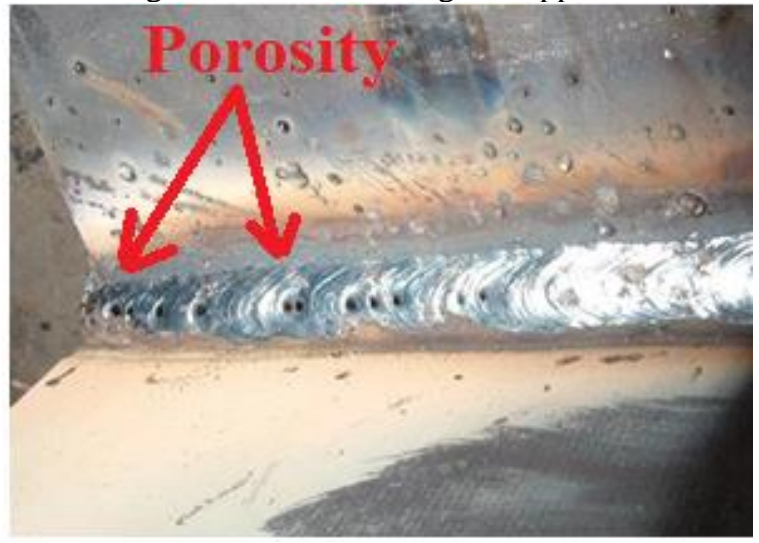

\subsubsection{Causes of Porosity:}

Fig.5 .Porosity

1. Electrode is not coated properly.

2. Using a longer arc may also increase its chances.

3. Increased welding currents.

4. Rust or oil on the weld surface.

5. Presence of moisture.

6. Improper use of shielding gas.

7. Incorrect surface treatment.

\subsubsection{Remedies for porosity:}

1. Proper selection of the electrode. 
2. Reduce the welding current.

3. Use the smaller arc length and slowing the process to allow the gases to escape.

4. Remove rust or oil from the surface and use a proper technique.

\subsection{Overlap}

When the weld face extends beyond the weld toe, then this defect occurs. In this condition the weld metal rolls and forms an angle of less than 90 degrees. Use correct arc distance.

\section{Overlap}

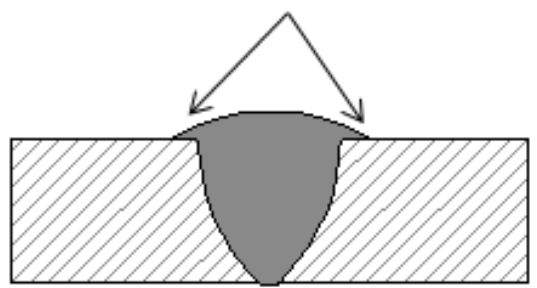

Fig.6 Overlap

\subsubsection{Causes of Overlap:}

1. Improper welding technique.

2. By using large electrodes.

3. To high welding current.

\subsubsection{Remedies for Overlap:}

1. Using a proper technique for welding.

2. Use a small electrode.

3. Less welding current.

4. Clean the surface before weld.

\subsection{Crater}

It occurs when the crater is not filled before the arc is broken, which causes the outer edges to cool faster than the crater. This causes a stress and then crack is formed.

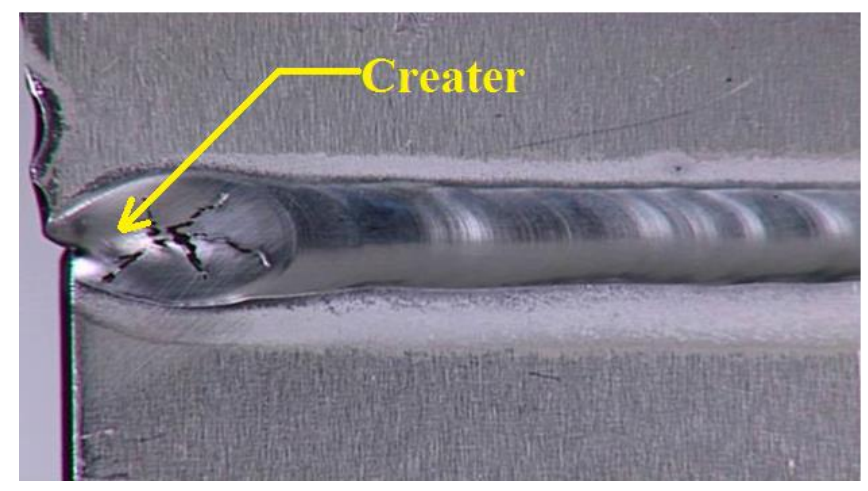

Fig.7. Crater and crack

\subsubsection{Causes of the crater:}

1. Incorrect Electrode/torch angle.

2. Use of large electrode

3. Improper welding technique

\subsubsection{Remedies for crater:}

1. Using a proper torch angle may reduce the stress on the metal 
2. Using a small electrode may also decrease the crater.

3. Use a proper technique.

\subsection{Internal Welding Defects}

The various types of internal welding defects with their causes and remedies are listed below:

\subsection{Slag Inclusion}

If there is any slag in the weld, then it affects the toughness and metal weldability of the given material. This decreases the structural performance of the weld material. Slag is formed on the surface of the weld or between the welding turns.

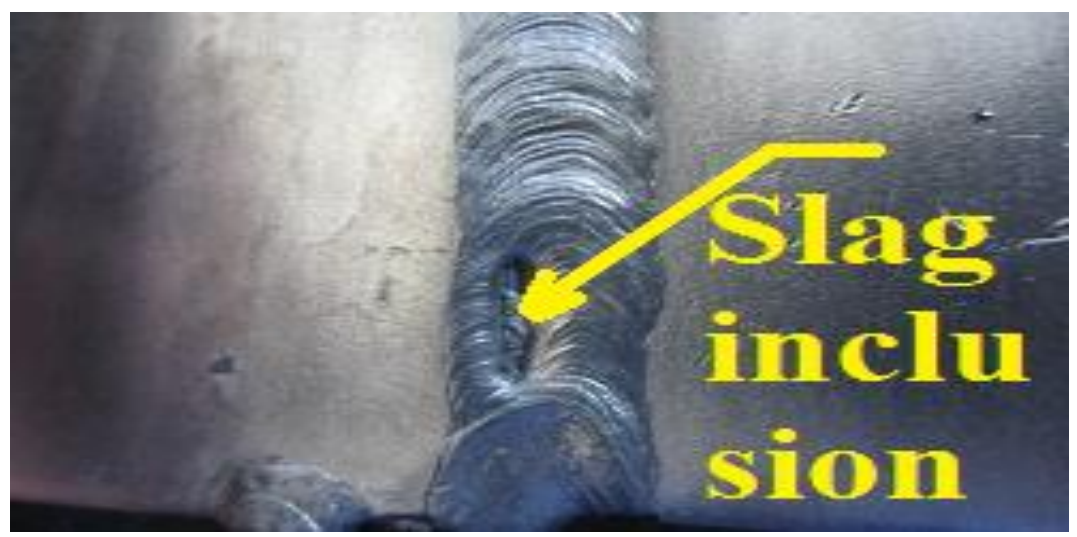

\subsubsection{Causes of Slag:}

Fig.8 Slag inclusion in a weld

1. Welding current density is very low.

2. Welding speed is very fast.

3. Edge of the weld surface is not cleaned properly.

4. Improper welding angle and travel rate of welding electrode.

5. Weld pool cools down too fast.

6. Welding current is too low.

\subsubsection{Remedies for Slag Inclusion:}

1. Increase the current density

2. Adjust the welding speed.

3. Clean the weld edges and remove the slags of previous weld layers.

4. Proper electrode angle and travel rate.

5. Reduce rapid cooling.

6. Remove any slag from the previous bead.

\subsection{Incomplete Fusion}

Incomplete fusion occurs when the welder does not accurately weld the material and the metal pre solidifies which leads to a gap which is not filled with the molten metal. 


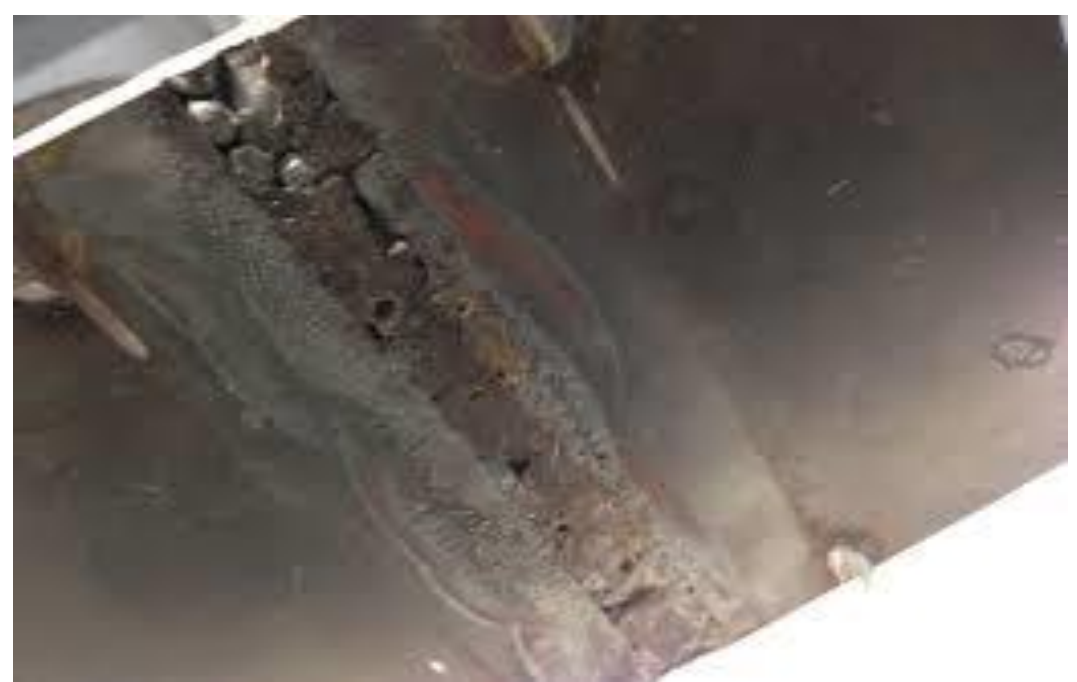

\subsubsection{Causes of Incomplete fusion:}

Fig.9 Incomplete fusion

1. Due to low heat input.

2. Weld pool is very large and runs ahead of the arc.

3. Angle of the joint is too low.

4. Incorrect electrode and torch angle may also lead to incomplete fusion.

5. Surface contamination.

6. Travel speed is too fast.

\subsubsection{Remedies for Incomplete Fusion:}

1. Use a sufficiently high welding current with the appropriate arc voltage.

2. Reducing the deposition rate.

3 . Increasing the joint angle.

4. Try to position the electrode and torch angle properly so that the edges of the plate melt away.

5. Positioning the bead properly.

6. Before begin welding, clean the workpiece.

\subsection{Necklace Cracking}

It occurs in the use of electron beam welding where the weld does not penetrate properly. Therefore, the molten metal does not flow into the cavity and results in a cracking known as "Necklace Cracking".

\subsubsection{Causes of Necklace Cracking:}

1. Improper welding technique.

2. It occurs in materials such as nickel base alloys, stainless steel, carbon steels, and Tin alloys.

3. Using the high speed of electron beam welding

\subsubsection{Remedies for Necklace Cracking:}

1. Using a proper welding technique.

2. Using proper materials for welding.

3. Using a constant speed during the welding process.

3. Improper welding technique

4. Incompletely Filled Groove

\subsection{Incomplete Penetration}


These defects occur only in the butt welds where the groove of the metal is not filled completely. It is also called as incomplete penetration defect.

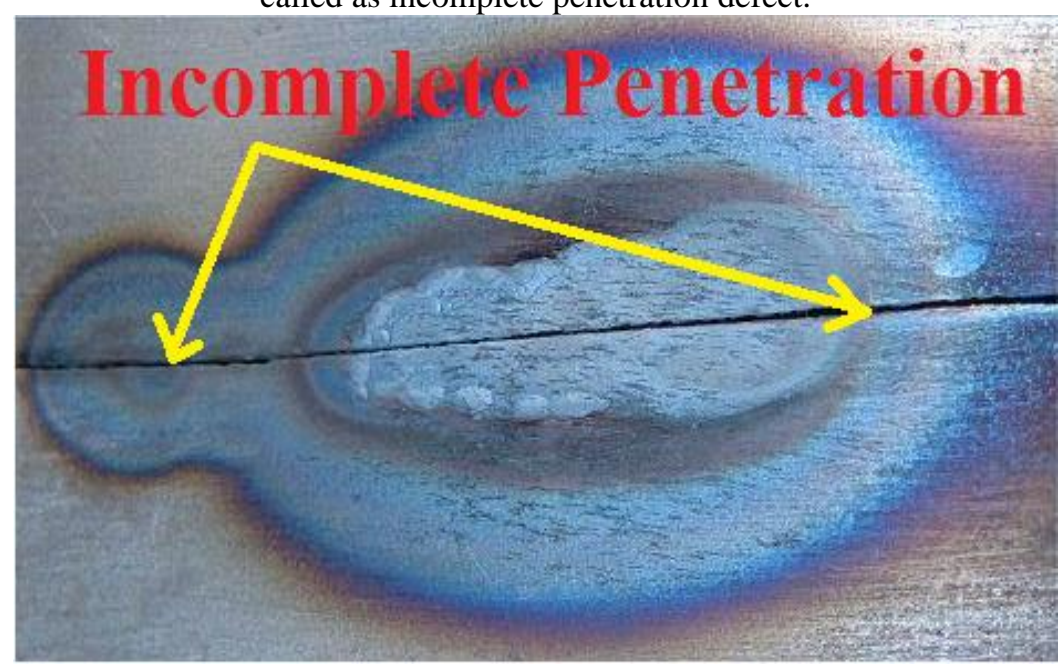

Fig.10 Incomplete penetration

\subsubsection{Causes of an incomplete filled groove}

1. Less deposition of the weld metal

2. Use of improper size of the electrode

3. Improper welding technique.

4. There was too much space between the weld metal.

5. Too low amperage.

6. Large electrode diameter.

\subsubsection{Remedies for Incomplete filled groove}

1. More deposition of the weld metal.

2. Use the proper size of the electrode.

3. By using a proper welding technique.

4. Use proper joint geometry.

5. Reduce arc travel speed.

6. Choose proper welding current.

7. Check for proper alignment.

\section{CONCLUSION}

In this review article, various welding defects are studied for causes and their remedies. Welding defects usually affect weld quality and longevity. This study (Review paper) will definitely be helpful in improving the productivity and yield of the welding. Rejections of the weld structure on the basis of the welding defect should be as minimized and all the above research is heading in the same direction. Therefore, it was tried to enlist all types of welding defects present in any manufacturing or production operation. By referring different research papers causes and their remedies are listed. While welding, it is very important to remove all the defects of welding present in the workpiece.if there would be defects present in the welding material, then in severe conditions the components of the material would fail which may lead to loss of property and sometimes also life.

\section{REFERENCES}

[1] Saadat Ali Rizvi, Wajahat Ali, A textbook of Advanced Welding Technology, Kataria \& Sons (P) Ltd. New Delhi; 2009: pp.184-191.

[2] Handbook, W., "Welding processes", American Welding Society, Vol. 2, (1991), pp.8-14

[3] The ABC of arc welding and inspection by Kobe steel Ltd, pp.93. 
[4] Handbook on Welding Techniques, Government of India, Ministry of Railways, pp.52

[5] Fabrication and Welding Engineering, Roger Timings, Elsevier's Science \& Technology Rights Department in Oxford, UK, pp.501 